\title{
Level of Anti-FSH and Anti-LH Antibody in PCOS Women and Comparing it with Normal Control Group
}

\author{
Shafaq Hussein*, Ihsan Al-Saimary and Maysoon Sherif
}

Department of Microbiology, College of Medicine, University of Basrah, Iraq

\begin{abstract}
Background: Polycystic ovary syndrome is commonest endocrine disorder of female at reproductive age with estimation of its prevalence in general population was $20-33 \%$.

Objective: To estimate the levels of Anti-FSH Ab, Anti-LH Ab in polycystic women and comparing it with healthy control group.

Patients and methods: This case controls study was carried out in Basrah. In this study blood sample from 29 women with PCOS and 29 healthy control women were collected from outpatient and private gynecological clinics and primary health care centers from different area of Basra from August 2016 to March 2018 for estimation of their serum levels of Anti-FSH Ab, Anti-LH Ab by using enzyme linked immunosorbent assay technique.

Results: Serum levels of anti-FSH Ab, anti-LH Ab were elevated in PCOS women.

Conclusion: Serum levels of anti-FSH Ab, anti-LH Ab is highly statistically significance in PCOS women than in healthy control group.
\end{abstract}

Keywords: PCOS; Anti-FSH Ab; Anti-LH Ab; Serum levels

\section{Introduction}

Polycystic ovarian syndrome is a heterogeneous collection of signs and symptoms that form a spectrum of a disorder with a mild presentation in some women and a severe disturbance of reproductive, endocrine and metabolic function in others. The pathophysiology of polycystic ovary syndrome appears to be multifactorial and polygenic. Key features include menstrual cycle disturbance, hyperandrogenism and obesity [1].

Polycystic ovaries are commonly detected by ultrasound or other forms of pelvic imaging, with estimates of the prevalence in the general population is $20-33 \%$ [2].

PCOS is characterized by chronic anovulation, hyperandrogenism, and insulin resistance (IR) [3]. Additionally, PCOS is often associated with obesity and a subsequent increased risk for type 2 diabetes [4].

The human ovary can be the target of an autoimmune attack in various circumstances, including several organ specific or systemic autoimmune diseases. And the presence of a specific antibody is a commonly accepted marker of an autoimmune disease and serves to differentiate autoimmune and non-autoimmune pathologic conditions for both clinical practice and further research studies, other pathologies involving the ovaries, such as unexplained infertility, PCOS and endometriosis have been associated with anti-ovarian autoimmunity [5]. Beside the confirming of ovarian autoimmunity, anti-FSH antibody may interfere with the endogenous or exogenous FSH function; antiFSH antibody may interact with FSH and form immune complexes so provoke its clearance. Also, anti-FSH could interfere with the FSH binding with its receptors [6]. It was found that autoantibodies to a specific FSH beta epitope were more prevalent in endometriosis and polycystic ovary syndrome (PCOS) [7].

\section{Aims of the Study}

To estimate the level of anti-follicle stimulating hormone antibody and anti-luteinizing hormone antibody in polycystic women and comparing to normal control group.

\section{Materials and Methods}

\section{Patients}

A total number of 29 women with PCOS was involved in this case control study. Patients where collected from outpatient and private gynecological clinics from different area of Basra regardless the marital status, whom age ranged from 20-40 years. The diagnosis of PCOS was based on Androgen Excess and PCOs society at 2006 criteria:

(1) oligo-and/or anovulation,

(2) clinical and/or biochemical signs of hyperandrogenism (patients presented with hirsute, acne or alopecia, and/or increased circulating levels of testosterone; ) and estimation of $\mathrm{FSH}, \mathrm{LH}$, prolactin hormone in day 3 of the menstrual cycle,

(3) polycystic ovaries (ovarian morphology was assessed using transvaginal ultrasound),

(4) exclusion criteria.

All patients with hormonal therapy or any medication known to interfere with follicular development or hormonal levels under the study for last 4 months of sample aspiration. All patients with oligomenorrhea, amenorrhea due to other than PCOS causes.

*Corresponding author: Shafaq Hussein, Department of Microbiology College of Medicine, University of Basrah, Iraq, Tel: +9647703143884; E-mail: shafaqalmusawy@gmail.com

Received January 09, 2018; Accepted January 24, 2018; Published January 27 2018

Citation: Hussein S, Al-Saimary I, Sherif M (2018) Level of Anti-FSH and AntiLH Antibody in PCOS Women and Comparing it with Normal Control Group. Immunochem Immunopathol 4: 129. doi: 10.4172/2469-9756.1000129

Copyright: () 2018 Hussein S, et al. This is an open-access article distributed under the terms of the Creative Commons Attribution License, which permits unrestricted use, distribution, and reproduction in any medium, provided the original author and source are credited. 
Citation: Hussein S, Al-Saimary I, Sherif M (2018) Level of Anti-FSH and Anti-LH Antibody in PCOS Women and Comparing it with Normal Control Group. Immunochem Immunopathol 4: 129. doi: 10.4172/2469-9756.1000129

\section{The control group}

Consist of 29 fertile women collected from primary health care centers in Basra and who have regular menstrual cycle with no sign of hyperandrogenism and their age between 20-40 years and subjected to ultrasound examination and have normal hormonal level.

Body Mass Index (BMI) was calculated as follows: weight (kilograms)/height ${ }^{2}$ (meters).

\section{Methods}

Blood sample was collected in clot activator tube, serum was separated after centrifugation and divided in to two Eppendorf tubes to avoid multiple freezing and thawing and kept frozen until time of analysis to be tested by enzyme linked immunosorbent assay.

\section{Results}

\section{Basic subject characteristics}

This is a case control study involved 29 patients with PCOS obtained from outpatient and private clinics in period between August 2016 and March 2018. These were compared with age matched 29 apparently healthy controls. The basic subject characteristics are shown in Table 1. There was no significant difference in mean age, BMI or age group distribution between cases and controls. Around half of the patients (54.8\%) have an evidence of hyperandrogenism and only three patients (4.1\%) have normal menstrual cycle.

\section{Anti-FSH and anti-LH antibodies}

The levels of anti-gonadotropins are shown in Table 2, there's no significant difference in the levels of anti-gonadotropin $\mathrm{AB}$ between PCOS women and control group.

\section{Effect of obesity on anti-gonadotropin antibodies in PCOS}

Table 3 shows the effect of obesity anti-gonadotropins antibodies levels in patients with PCOS. There is no significant difference in the level of these antibody between obese and non-obese polycystic ovary women.

The effect of hyperandrogenism on study parameters is shown in Figure 1. Hyperandrogenism caused no significant difference in antigonadotropins antibodies.

On the other hand, those with history of infertility had higher levels of anti-FSH antibodies, but the difference didn't reach statistical significance (Figure 2).

The effect of LH/FSH ratio on anti-gonadotropin antibodies in PCOS women is shown in Figure 3, there is no statistically significant difference in anti-angiotensin antibodies in PCOS women with LH/ FSH ratio more than 3 or less than 3 .

\section{Discussion}

Immune system is affected by estrogen /progesterone ratio [8]. Patients with PCOS present low level of progesterone due to oligo/ anovulation therefore the immune system could be overstimulated by excess estrogen leading to production of autoantibodies in these patients [9]. Several mechanisms related to estrogen effects on the immune system, Estrogens increase the secretion of IL-4, IL-1, IL-6 and interferon- $\gamma$. The stimulatory effect of estrogens on the immune system could be inhibited by progesterone [10].

It had been showed that epitopes of beta-FSH are an autoantigen in women present with ovarian autoantibodies [11]. It is found that administration of therapeutic human gonadotrophin hormones or FSH for induction of ovulation in infertile ladies may induce immunological reaction to these therapeutic agents leading to decrease their efficacy and induce anti-gonadotropin antibody or anti-follicular stimulating hormone antibodies formation and this immune reaction might range from mild and transient to severe immunological reaction [12].

In this study, $95 \%$ of cases had menstrual disturbance, $54 \%$ of cases had hyperandrogenism, and $68 \%$ of cases had infertility. Menstrual irregularity might be considered as a marker for insulin resistance in PCOS. oligomenorrhea has been associated with hyperinsulinemia and with increased prevalence and future risk of type II diabetes mellitus [13]. It is found that PCOS women had infertility rate 66\% [14].

In the present research it had been found that the mean anti-FSH antibody level in PCOS women (lean and obese) is $(22.1 \pm 39.1 \mathrm{ng} / \mathrm{ml}$ )

\begin{tabular}{|c|c|c|c|c|}
\hline & & Cases $(\mathrm{No}=29)$ & Controls $(\mathrm{No}=29)$ & p Value \\
\hline & $\begin{array}{l}\text { Age (years) } \\
\text { Mean } \pm \text { SD }\end{array}$ & $27.7 \pm 5.8$ & $29.4 \pm 5.7$ & 0.082 \\
\hline & $\begin{array}{l}\mathrm{BMI}\left(\mathrm{Kg} / \mathrm{m}^{2}\right) \\
\text { Mean } \pm \mathrm{SD}\end{array}$ & $27.0 \pm 3.4$ & $26.0 \pm 3.3$ & 0.060 \\
\hline \multirow{5}{*}{$\begin{array}{l}\text { Age } \\
\text { groups }\end{array}$} & 18-20 years: No (\%) & $5(6.8 \%)$ & $6(8.2 \%)$ & \multirow{5}{*}{0.274} \\
\hline & $21-25$ years: No (\%) & $24(32.9 \%)$ & $13(17.8 \%)$ & \\
\hline & $26-30$ years: No (\%) & $17(23.3 \%)$ & $20(27.4 \%)$ & \\
\hline & 31-35 years: No (\%) & $18(24.7 \%)$ & $19(26.0 \%)$ & \\
\hline & $\geq 36$ years: No (\%) & $9(12.3 \%)$ & $15(20.5 \%)$ & \\
\hline \multicolumn{2}{|c|}{ History of infertility: No (\%) } & $50(68.5)$ & $0(0.0 \%)$ & 0.0 \\
\hline \multicolumn{2}{|c|}{ Oligomenorrhea: No (\%) } & $70(95.9 \%)$ & $0(0.0 \%)$ & 0.0 \\
\hline \multicolumn{2}{|c|}{ Hyperandrogenism: No (\%) } & $40(54.8 \%)$ & $0(0.0 \%)$ & 0.0 \\
\hline
\end{tabular}

Table 1: Basic subject's characteristics.

\begin{tabular}{|l|l|l|l|l|l|}
\hline & & No. & Mean \pm SD & Range & p Value \\
\hline \multirow{2}{*}{ Anti-LH Ab } & cases & 29 & $79.6 \pm 49.9$ & $(11.6-271.2)$ & \multirow{2}{*}{0.051} \\
\cline { 2 - 6 } & controls & 28 & $101.4 \pm 30.1$ & $(74.6-231.5)$ & \\
\hline \multirow{2}{*}{ Anti-FSH Ab } & cases & 29 & $22.1 \pm 39.1$ & $(3.5-161.3)$ & \multirow{2}{*}{0.628} \\
\cline { 2 - 5 } & controls & 29 & $26.4 \pm 27.9$ & $(5.9-134.4)$ & \\
\hline
\end{tabular}

Table 2: Anti-gonadotropin antibodies in cases and controls.

\begin{tabular}{|c|c|c|c|}
\hline & $\begin{array}{c}\text { Normal } \\
\left(\mathbf{B M I} \leq \mathbf{2 5} \mathbf{~ K g} / \mathbf{m}^{\mathbf{2}}\right)\end{array}$ & $\begin{array}{c}\text { Preobese and Obese } \\
\left(\mathbf{B M I}>\mathbf{2 5} \mathbf{~ K g} / \mathbf{m}^{\mathbf{2}}\right)\end{array}$ & $\mathbf{p}$ Value \\
\hline Anti-LH Ab & $1.80 \pm 1.70$ & $1.50 \pm 1.24$ & 0.553 \\
\hline Anti-FSH Ab & $102.1 \pm 68.0$ & $65.9 \pm 29.3$ & 0.056 \\
\hline
\end{tabular}

Table 3: Effect of obesity on anti-gonadotropin antibodies in PCOS.

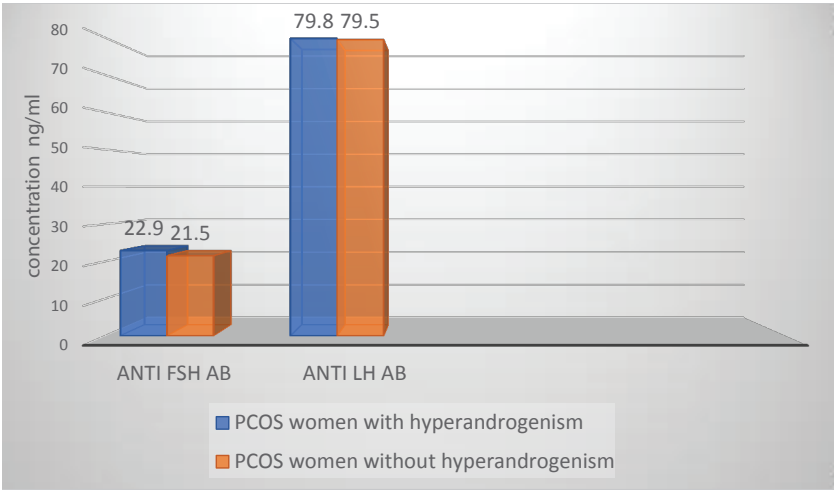

Figure 1: Effect of hyperandrogenism on the level of anti-FSH antibody and anti-LH antibody. 
Citation: Hussein S, Al-Saimary I, Sherif M (2018) Level of Anti-FSH and Anti-LH Antibody in PCOS Women and Comparing it with Normal Control Group. Immunochem Immunopathol 4: 129. doi: 10.4172/2469-9756.1000129

Page 3 of 4

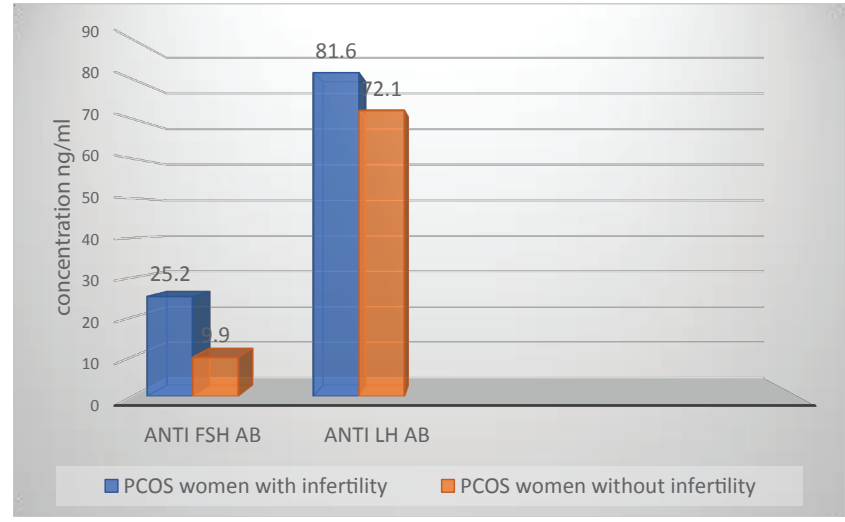

Figure 2: Effect of infertility on anti-FSH AB and anti-LH AB level.

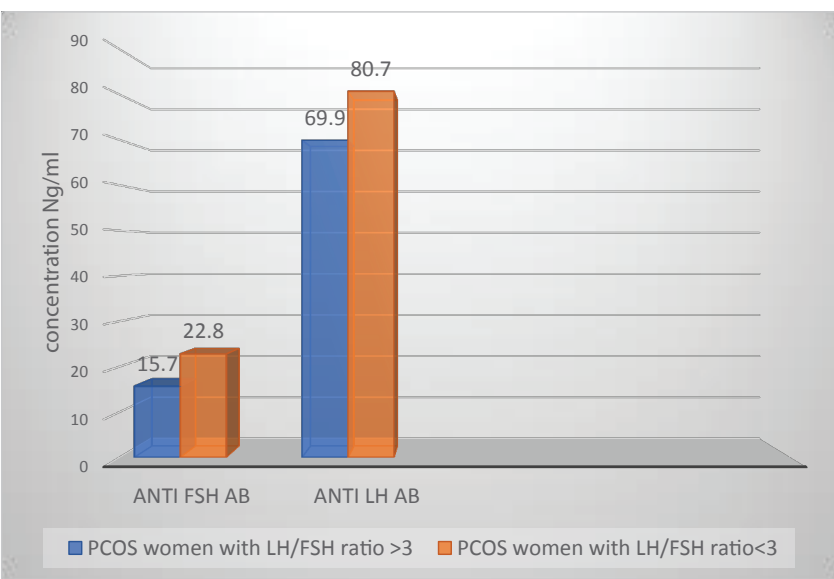

Figure 3: Effect of LH/FSH ratio on anti-gonadotropin antibodies in PCOS women.

and normal control group $(26.4 \pm 27.9 \mathrm{ng} / \mathrm{ml})$ so this result revealed that the difference in the anti-FSH antibody level of in polycystic ovaries women comparing to control group was not of statistically significant ( $\mathrm{p}$ value $>0.05$ ) and also I found no difference in anti-FSH $a b$ level between obese or lean PCOS women ( $\mathrm{P}$ value $>0.05$ ) and also no difference in its level in polycystic ovaries ladies in the presence of hyperandrogenic status or in absence of hyperandrogenic status. There is increasing in the anti-FSH antibody level in presence of infertility, but it did not reach the level of statistical significance and this agreed with study done in Iraq [15]. On the other hand this finding dis agreed with [16] in Estonia who found the anti-FSH antibody of is statistically higher in infertile PCOS than in control group. Also I find that the mean level of anti-LH in PCOS women $(79.6 \pm 49.9 \mathrm{ng} /$ $\mathrm{ml})$ and in control group was $(101.4 \pm 30.1 \mathrm{ng} / \mathrm{ml})$ indicating that the difference in the anti-LH antibody levels in between polycystic ovaries ladies and normal control group was not of statistical significant and also I conclude that the difference in anti-LH antibody level between obese polycystic ovaries ladies $(1.50 \pm 1.24 \mathrm{ng} / \mathrm{ml})$ and lean polycystic ovaries women $(1.80 \pm 1.70 \mathrm{ng} / \mathrm{ml})$ was not statistically significant $(\mathrm{P}$ value $>0.05$ ) also, no difference is found in anti-LH antibody in case of infertility or in case of fertile polycystic ovaries women and no difference in case of primary or secondary infertility.

The common feature for the PCOS is the disturbed regulation of the immune system and this disturbance of the immune system may lead to production of antibodies and development of autoimmunity, our study is part of the study that done to detect that the PCOS is an auto immune disease.

\section{Conclusions}

Researcher found that autoantibodies directed to hormones are produced when hormones levels above the physiological level [17], in this study the level of FSH $(4.13 \pm 1.7)$, LH $(5.40 \pm 2.42)$ in PCOS women within normal range that could not stimulate the production of auto antibodies so the presence of these antibodies in polycystic women and healthy control group support the hypothesis that these antibodies are naturally occurring antibodies. Any disturbance in the normal hormones level could be considered as a primary diagnostic clue of suspected pathology. The diagnosis of auto immune disease usually ensured by the measurement of specific auto-antibodies. Despite of the mechanisms that may be involved in the autoimmune pathogenesis, the presence of specific autoantibodies is still the main practical, clinical and research indicators for diagnosis of autoimmune diseases [5]. There is no previous study done on the level of anti-LH antibody in PCOS on the other hand theirs study for detection of this antibody in case of infertility and primary ovarian failure done by Haller [7].

\section{References}

1. Edmonds K (2012) Dewhurst's textbook of obstetrics \& gynaecology. Wiley Blackwell Science, London, UK, pp: 513-521.

2. Sirmans S, Pate K (2014) Epidemiology, diagnosis, and management of polycystic ovary syndrome. Clinical Epidemiology 6: 1-13.

3. Dunaif A (1997) Insulin resistance and the polycystic ovary syndrome: mechanism and implications for pathogenesis. Endocr Rev 18: 774-800.

4. Legro R, Kunselman A, Dodson W, Dunaif A (1999) Prevalence and predictors of risk for type 2 diabetes mellitus and impaired glucose tolerance in polycystic ovary syndrome: a prospective, controlled study in 254 affected women. J Clin Endocrinol Metab 84: 165-169.

5. Luborsky J (2002) Ovarian autoimmune disease and ovarian autoantibodies. $J$ Womens Health Gend Based Med 1: 585-599.

6. Warren G, O'Farrell L, Rogers K, Billings K, Sayers S, et al. (2006) CK-MM autoantibodies: prevalence, immune complexes, and effect on CK clearance. Muscle Nerve 34: 335-346.

7. Haller K, Mathieu C, Rull K, Matt K, Bene M, et. al. (2005) IgG, IgA and IgM antibodies against FSH: serological markers of pathogenic autoimmunity or of normal immunoregulation. Am J Reprod Immunol 54: 262-269.

8. Khan D, Ansar S (2016) The immune System is a natural Target for estrogen Action: Opposing effects of estrogen in Two Prototypical Autoimmune Diseases. Front Immunol 6: 635.

9. Samsami D, Razmjoei P, Parsanezhad M (2014) Serum levels of antihistone and anti-double-strand DNA antibodies before and after laparoscopic ovarian drilling in women with polycystic ovarian syndrome. J Obstet Gynaecol India 64: 47-52.

10. Angstwurm M, Gartner R, Ziegler-Heitbrock H (1997) Cyclic plasma IL6 levels during normal menstrual cycle. Cytokine 9: 370-374.

11. Gobert B, Joliviet-Reynaud C, Dalbon P, Barbarino Monnier P, Faure G, et al. (2001) An immunoreactive peptide of the $\mathrm{FSH}$ involved in autoimmune infertility. Biochem Biophys Res Commun 289: 819-824.

12. Morte C, Celia C, Geyer C, Urbancsek J, Lletget B, et al. (2018) Assessment of the immunogenicity of gonadotrophins during controlled ovarian stimulation. Am J Reprod Immunol, p: 78

13. Solomon C, Hu F, Dunaif A, Edwards J, Stampfer M, et al. (2002) Menstrual cycle irregularity and risk for future cardiovascular disease. J Clin Endocrinol Metab 87: 2013-2018.

14. Joham A, Teede H, Ranasinha S, Zoungas S, Boyle J (2015) Prevalence of Infertility and Use of Fertility Treatment in Women with Polycystic Ovary Syndrome: Data from a Large Community-Based Cohort Study. J Women Health 24: 299-307. 
Citation: Hussein S, Al-Saimary I, Sherif M (2018) Level of Anti-FSH and Anti-LH Antibody in PCOS Women and Comparing it with Normal Control Group. Immunochem Immunopathol 4: 129. doi: 10.4172/2469-9756.1000129

Page 4 of 4

15. Akram $\mathrm{H}$ (2016) Anti-follicle stimulating hormone antibodies in polycystic ovary syndrome and appearantly healthy controls. World J Pharm Res 5: 32-38.

16. Kadri HK, Salumets A, Uibo R (2012) Review on Autoimmune Reactions in Female Infertility: Antibodies to Follicle Stimulating Hormone. Clinical and
Developmental Immunology 2012: 1-15.

17. Thomas $\mathrm{J}$ (2001) Antigen-specific responses in autoimmunity and tolerance. Immunol Res 23: 235-244. 